\title{
RISK ANALYSIS ON THE HEAT PUMP SYSTEM TO USE FOR BUILDING HEATING, IN URBAN AREA
}

\author{
Article DOI:https://doi.org/10.35219/mtd.2019.2.01 \\ Cristina CALIN ${ }^{1)}$, Eugen RUSU ${ }^{2)}$, Stefan DRAGOMIR ${ }^{3)}$ \\ ${ }^{1}$ CALORGAL S.A.Galati, Romania \\ ${ }^{2}$ University of -Dunarea de Josll /Faculty of Engineering, Galati, Romania \\ ${ }^{3}$ University of -Dunarea de Jos\|/Faculty of Engineering, Galati, Romania \\ *Corresponding author: doromir_dragomir@yahoo.com
}

\begin{abstract}
The precautionary principle for each Member State of the European Community is to protect the environment when developing an investment. The European Union has adopted the own strategy for the fight against climate change, through the adoption of a plan for sustainable growth, Europe in 2020, which has established a set of objectives in the field of energy. A solution to produce thermal energy without polluting emission would be to use Earth geothermal energy. It is necessary to implement for heating, a system of heat pumps for individual residential properties or building assemblies from inside the urban areas.
\end{abstract}

KEYWORDS: heat pump, risk analyze, sustainable development

\section{INTRODUCTION}

Environmental safety aims to achieve a better quality of life for the present and future generations. The European Union's Heating and Cooling (IR) strategy promotes the development of cogeneration and three generation units (electricity, heating and cooling). For this reason, distributed production is encouraged, as far as it proves to be economically feasible.

Research on the use of the precautionary principle identified the following should be considered:

- recognition of ignorance,

- the long-term monitoring requirement,

- consideration of benefits and risks,

- ensuring the use of knowledge at local level, as well as the expertise of the specialists.

In many cities in Romania, municipal heating systems (SACETs) have faced over the past 25 years with massive functionally disruptions and for that the consumers implement individual heating solutions. Also, if risk management options are to be assessed (impact if there is a change in legislation), it is useful to specify the options within the conceptual model choice for building heating.

Geothermal energy is the natural heat captured from the Earth, for building heating. The geothermal resource is clean, renewable, because the heat emanating from the Earth's interior is inexhaustible. The geothermal energy source is available 24 hours a day, 365 days a year.

Heat that continually flows from within the Earth is estimated to be equivalent to 45 million megawatts and a megawatt can supply the energy needs of 1000 individual houses.

The environmental impact of using geothermal energy is rather small and controllable. Emissions of nitrogen oxide, hydrogen sulphide, sulfur dioxide, ammonia, methane, dust and carbon dioxide emissions are extremely small, especially when compared to emissions from fossil fuels.

The geothermal heating system consists of a heat pump and a circuit made of energy-capturing pipes, mounted underground (horizontally or vertically) or at the bottom of the water basins. Heat pumps can be: with horizontal sensors, deep-water (or vertical) heat pumps and water-water heat pumps.

Pumps with horizontal caps are cheaper but, for their installation, it is necessary a space around the building twice the living space. However, waterwater pumps are still the most efficient, with the pipe circuit being installed at the bottom of the water tanks.

Vertical heating pumps are the most expensive because the cost of equipment is 2-3 million Euros, plus costs for soil analysis. 


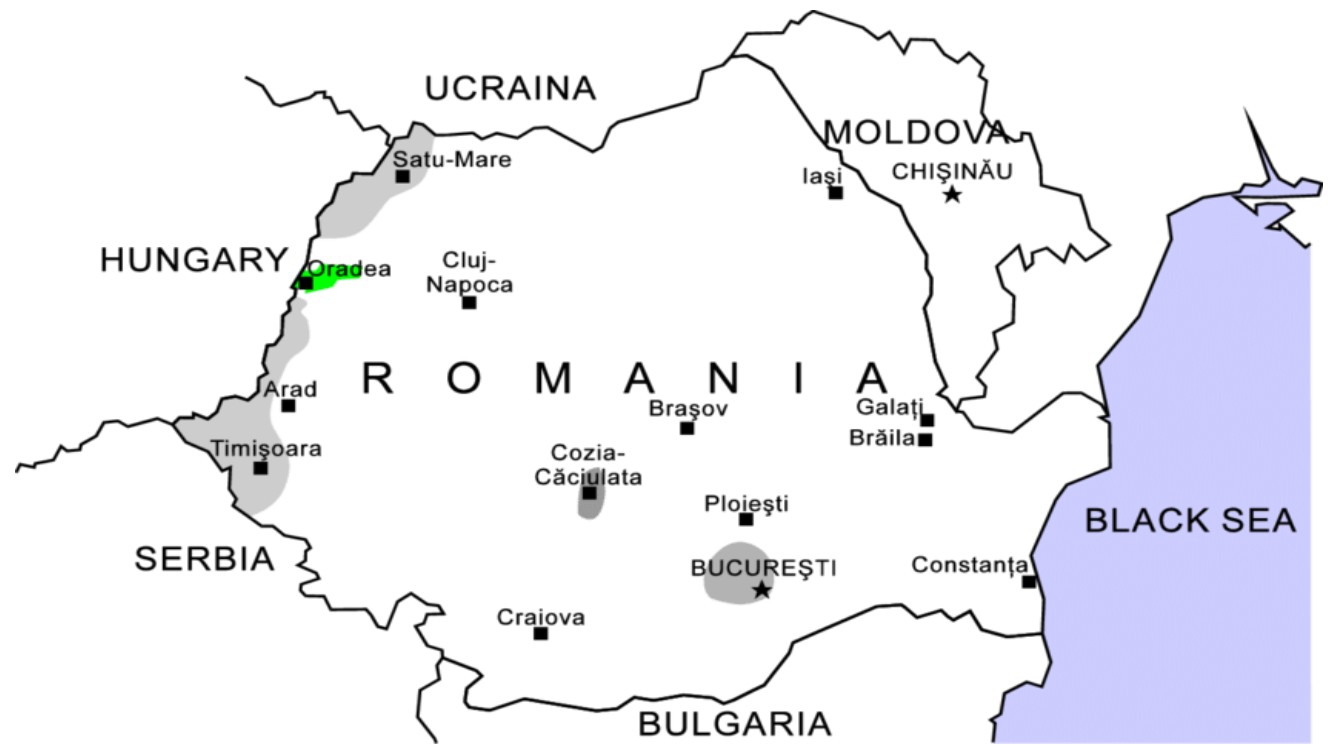

Fig. 1. Map with geothermal resource from Romania [5]

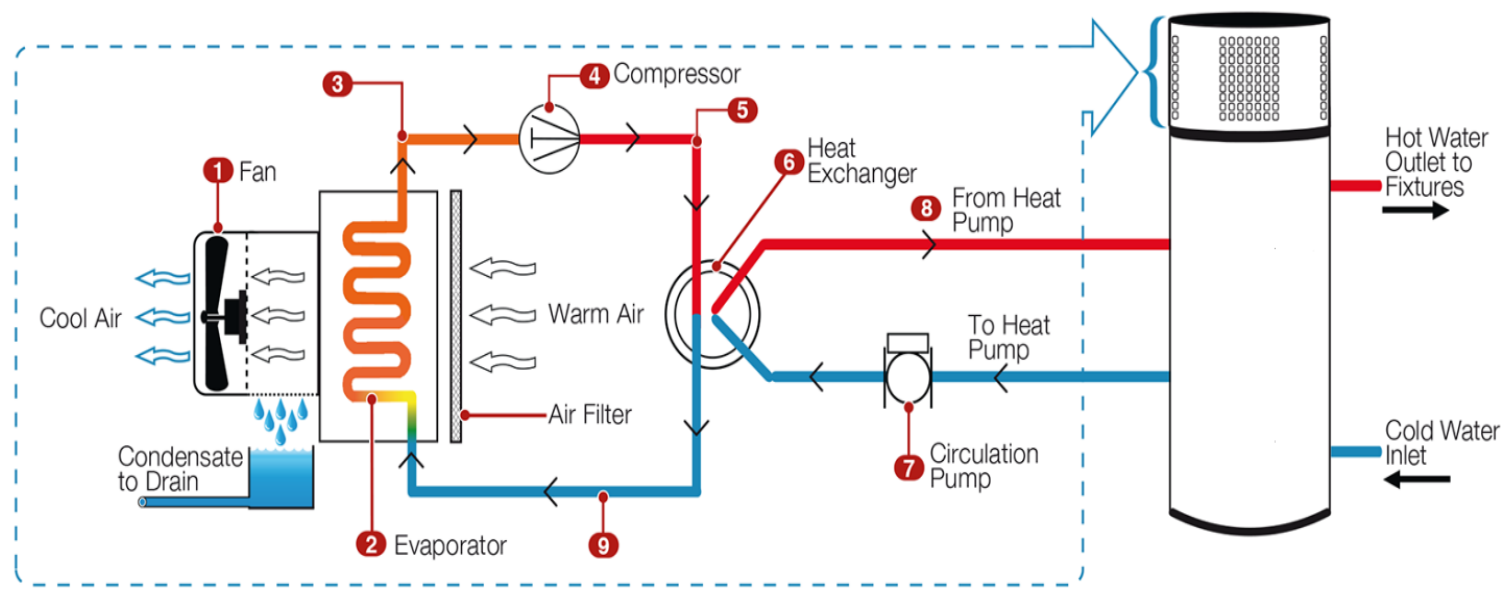

Fig. 2. Heat pump system [6]

The basic components and the operating principle of a heat pump are described in Fig. 2.

It has also been recognized that achieving environmental security requires collective partnership approaches to decision-making for environmental protection. Environmental management strategies must, therefore, consider economic demands and social needs, with the capacity of the environment to cope with discharges, pollution and other perturbations.

The heat pump system chooses whit heat exchanger by switching a valve the supplying heat of your home. The material that makes up the condenser and evaporator should be copper. Copper is resistant to the corrosion. Aluminum is much cheaper, but the risk to corrode is greater than copper.

The process moves heated air from a single source, which is at a lower temperature (cool) or higher temperature (heat), to a heat sink at another location.

Efficiency heating or cooling pump is how much energy can produce, as compared to how much energy you put into running it.
A classic furnace product $97 \%$ of the energy in the form of heat for home and the other $3 \%$ is lost up the flue.

Electric device for heating has no flue and $100 \%$ of the energy stays in home in the form of heat.

If the geothermal heat pump is adopted, for the first, it must calculate the geothermal heat pump efficiency.

Efficiency of geothermal heat pump is traditionally measured using a ratio called "coefficient of performance" (COP). The COP [2] of a geothermal heat pump is the ratio of the heating or cooling output to the energy input to run the machine. When the value of COP is over 1.0 the heat pump is performing very efficiently. A heat pump is the only heating and cooling device that has a COP over 1.0 .

\section{CALCULATING THE PERFORMANCE COEFFICIENT OF THE HEATING SYSTEM}

To make that calculus, the engineer need: 
1. energy out (Watts) or the heat pump's expected output,

2. energy in (Watts), or how much energy it takes to run the heat pump.

Using these two values, the authors calculate COP with formulas:

$$
C O P=\frac{\text { Energy out }}{\text { Energy in }}
$$

In an example of calculation, the authors use an air heat pump of 0.5 ton.

The heat pump is operating in heating mode on a closed ground loop. When the compressor is running in first stage, the energy delivered is about 2,500Watts and the heat pump consumes 0.800 Watts in function. Now, it can be calculated the COP:

$C O P=2,500 / 0.800=3.12$

For a lot of twenty residential building is necessary a water to air heat pump of 4 tones and the COP calculate is 3.12 .

That means, for every watt of electricity used to run this pump, the authors obtained 3.12 Watts of heat energy out of the pump. The extra output is free energy harvested from the ground loop by the heat pump. Put in terms of the efficiency, the authors conclude that the efficiency of the heat pump is $389 \%$.

By comparing the electric heating device, with soil-water heating pumps and geothermal pump system, the authors may say that geothermal system is very efficient [3]. In Table 1, a comparison is shown between the three heating system: electric device, soil-water heating pumps, and geothermal heating.

Table 1. Coefficient of Performance

\begin{tabular}{|c|c|c|c|}
\hline $\begin{array}{c}\text { Types of } \\
\text { heating } \\
\text { system }\end{array}$ & $\begin{array}{c}\text { Electric } \\
\text { device }\end{array}$ & $\begin{array}{c}\text { Soil- } \\
\text { water } \\
\text { pump }\end{array}$ & $\begin{array}{c}\text { Geothermal } \\
\text { system }\end{array}$ \\
\hline COP & 1.00 & 2.87 & 3.12 \\
\hline Efficiency & $100 \%$ & $287 \%$ & $312 \%$ \\
\hline
\end{tabular}

The values of COP and efficiency of building heating depending by types of heating system and operating conditions.. The output of the heat pump changes when in cooling mode, so does the COP.

The output changes depending on which stage the heat pump is operating.

For residential buildings, when the authors use a water-soil heat pump, is necessary that COP value to be 3.12 in stage 1 (no severe climate condition) and 4.10 in stage 2 (severe climate condition).

It can be estimated an average COP by adding these two together and dividing by two:

$$
(4.10+3.12) / 2=3.61
$$

This value helps us to choose the capacity required for the heating pump, that the authors want to use for the climate control of all the houses.

\section{RESEARCH AND MEASUREMENT ON THE RISK ON THE HEAT PUMP SYSTEM}

By assessment of impacts and vulnerability of heating system, will be created a risk report, to identify priority areas for action and compare different possible risks when the authors implement a heating system.

Inform the second Climate Change Risk Assessment (CCRA) and including a learning process within the project so that the expertise gained is retained in government and the wider research community. Climate projections combined with socio-economic assumptions can assess the magnitude of possible future consequences.

Accounting for the effects of autonomous adaptation and existing policies will provide an estimate of the „residual” consequences.

\subsection{Risk Management}

The dynamic of risk management is a phenomenon that is developing in space and time. This dynamic is depending of the context in which may be realized, technological process changes.

Such activities strengthen the evidence base that supports the risk management strategy and ultimately help to reduce the uncertainties that surround the risk problem.

This is particularly the case for those risks that might be deemed marginal in their magnitude or, because of their specific characteristics, are sensitive to change.

Examples include where the progressive erosion of cliffs increases the risks to people and property over time, or where changes to international border controls influences the likelihood of exotic animal disease agents entering a country.

The authors reinforce the most important aspects to take in consideration during the environmental risk assessment and management process.

The authors try to use expertise, information, skills, values, expectations, failures and successes as a result of the risk assessment and management process.

\subsection{Strategic Programs and Operational Risks}

Some of the key issues for consideration in comparing environmental risks with other business risk include the observations that:

The authors try to make strategic decisions on the needed priorities and for implementation of an operational program for the maintenance of the heating system.

Environmental risks frequently harbor more uncertainty that those associated with closed, engineered systems.

\subsection{Strategic Environmental Risks}

For some sectors, especially those operating in essential infrastructure (water companies, power utilities, waste companies, highways and rail network 
providers), future climate risks are likely to be a key consideration.

Other examples of strategic environmental risks may include the continued use of obsolete chemical products that are under revised legislation and supply-chain risks [1].

\subsection{Ethical Risks}

In addition to these technical environmental risks, institutions may also face ethical risks, posed by contentious developments, activities or future proposals.

In countries where native indigenous populations have accepted rights over specific natural resources, organizations may be required to manage corporate risks, initiated by perceived threats to cultural practices, spiritually significant land and ways of life.

These issues have been historically underplayed whilst organizations focused on establishing corporate risk frameworks, risk committees and champions and risk registers [3].

The authors have learnt from practice that cultural and business process elements of good risk management are critical.

These show us the importance of the organizational and people framework alongside the competent application of technical tools and process.

The authors considered, on one side, the uniqueness of each case taking into account the specific pollution, and on the other side the fact that each of them might be a representative case for the prospective sustainable development of Romanian industry.

The authors have also considered that the most appropriate research method is to exemplify the implementation of an ecological impact/risk assessment knowledge based method.

The authors argue that this better emphasizes the causality behind the involved pollution issues. The instruments of data collection were technical documentations and public surveys [3].

The impact of heating pump system on groundwater quality in relation to the climatic conditions, and on the mode of spatial planning and exploitation of the system, the authors considered that there is no possibility of contamination of groundwater due the use of heating pump system and all in accordance with National and European standards [4].

\subsection{About Risk Quantification for a Heat Pump System}

Risk quantification is based on a system where the probability and severity of an event are classified on the basis of an assigned score.

Quantification of severity factor is:

- 3 - high - major,

- 2 - average - medium,

- 1 - low - lightweight

Risk shall be calculated by multiplying the probability factor with a severity factor. In this way, it is possible to analyze the different risks, like in Figures 3 and 4.

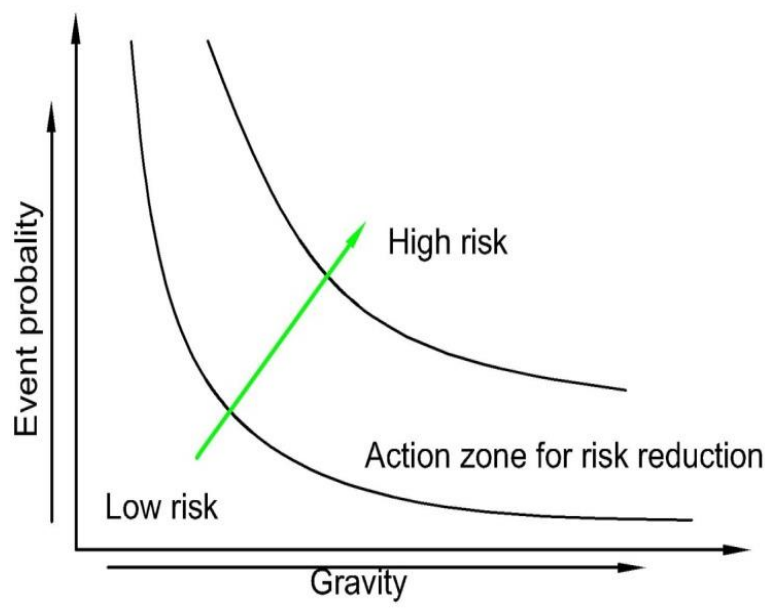

Fig. 3. Risk analysis

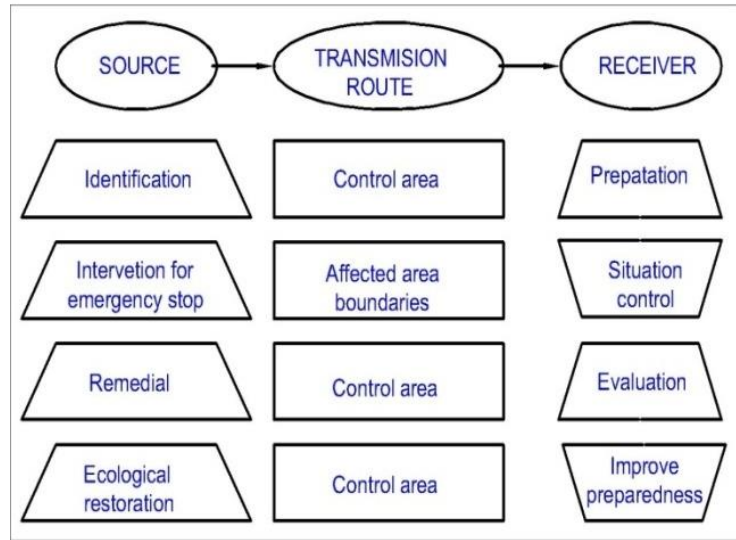

Fig. 4. Risk management

Advantages of risk management method shall consist of:

- allowing for a comparison between different areas, with condition that these area can be analyzed by the same basis indicators,

- allowing to compare the state of an area, at different time moments, offering traceability of various environmental factors, as well as the quality of the overall environment in the area in question,

- the ability to establish a direct relationship between the environment and population,

- $\quad$ ensuring active use of a large quantities of data on the environment state, obtained from the functioning of the monitoring system, at the national level.

The weaknesses of risk management method are:

$\checkmark$ limits for the indicators that characterize the environment at a given time and the proportion, thereof, in the determination of the environment quality,

$\checkmark \quad$ assessment of global status for the environment quality,

$\checkmark$ priority of the operation in areas which have been damaged by anthropogenic activities, 
$\checkmark \quad$ orientation of funds necessary for environmental rehabilitation.

\section{CALCULATION OF GLOBAL POLLUTION INDEX}

For calculus of global pollution index, the authors considered the next major environmental factors: air, water, soil and level of noise.

When it is considered a heating pump in function the authors could give a worthiness note, for the next factors: for air -8 ; for water -9 ; for ground -7 ; for noise - 9

The ideal status is represented by a regularly quadrilateral of the area $\mathrm{S} 1$.

Actual status is represented by an irregular quadrilateral with area S2, placed in the regular quadrangle, like it is shown in Fig. 5.

The allowed global pollution index is representing by the dividing $\mathrm{S} 1 / \mathrm{S} 2$.

General formula for calculating the quadrilateral area is in the case regular quadrilateral:

$l=N B=10$

A regular quadrilateral is achieved by means of calculations of a general formula:

$$
\begin{gathered}
A_{n}=\left(\frac{1}{2}\right) \cdot n \cdot \sin \left(\frac{360}{4}\right) \cdot l^{2} \\
l^{2}=10^{2}
\end{gathered}
$$

$S_{1}=\left(\frac{1}{2}\right) \cdot 4 \cdot \sin 90 \cdot 10^{2} \Leftrightarrow S_{1}=200$

$\mathrm{n}=$ the number of polygonal sides.

For the irregular quadrilateral (like the example):

$$
S_{2}=S_{I}+S_{I I}+S_{I I I}+S_{I V} \Leftrightarrow S_{2}=135
$$

The global pollution index will be:

$$
\frac{S_{1}}{S_{2}}=\frac{200}{135}=1.48
$$

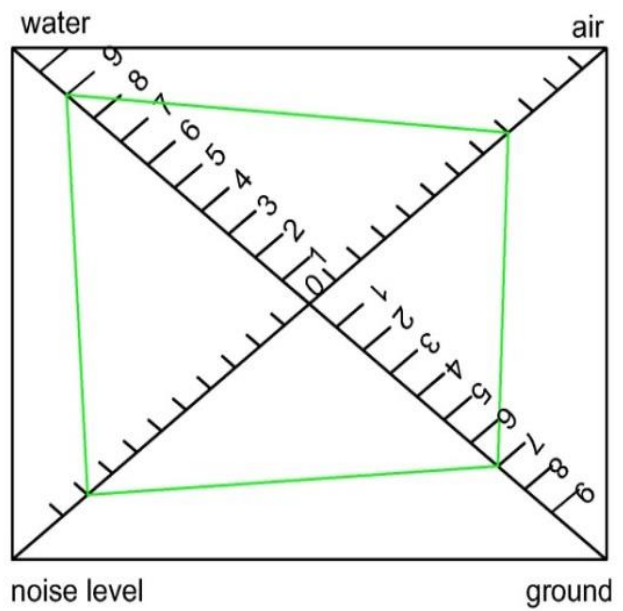

Fig. 5. Superposition of irregular quadrilateral on the regular quadrilateral of environment parameters

Economic factors could have a significant influence on the decision-making process and may affect the acceptability of a given option. In the case of flooding, for example, there are construction and maintenance costs associated with any flood risk management scheme; there may also be costs in terms of damage to the environment by habitat removal or alteration.

The best option is likely to be the one with the greatest excess of benefits over costs.

The costs are those social, regulatory and private costs of the control options, including construction, maintenance and environmental damage. This should include both those benefits and costs that can be associated and those that cannot (or for which robust monetary valuations are not readily available) the latter need to be assessed in physical and qualitative terms.

\section{CONCLUSIONS}

Geothermal energy has a relatively low potential at national level, but could cover a considerable part of the demand for heating energy in some localities, further studies are needed on the potential and economic competitiveness of this energy source so that it can be integrated on time in the projects for the modernization of the distribution networks of the thermal agent.

Much of the individual housing in Romania could provide part of the hot water demand by using solar panels. Their penetration needs a long process that requires the continuation and expansion of the "Casa Verde Plus program".

If the precautionary principle is adopted, decision-makers determine what action is necessary, taking into account the potential consequences of taking no action, the uncertainties inherent in the scientific evaluation, and consulting interested parties on the possible ways of managing the risk. An analysis on the most important factors that can be affected when there shall be established an investment that would create jobs but may affect the environment.

In accordance with the provisions of the national law no. 104/2011 on air quality, the responsibility for the monitoring authorities for the environment protection.

Monitored pollutants, methods of measurement, the limit values and alert thresholds, and for the provision of information and the criteria for location of the points of monitoring shall be laid down by the national law no. 278/2013 and they comply with the requirements laid down by European regulations on the matter. The adopted measures should be commensurate to the level of risk and to the desired level of protection.

An important advantage of installing a heat pump system is to save money. Heating and cooling the building by using this system mean an efficient energy economy. This heating pump system is more environmentally safe than other heating devices based on electricity, methane gas or fuel. 


\section{ACKNOWLEDGMENT}

This work was carried out in the framework of the research project REMARC (Renewable Energy extraction in Marine environments and its Coastal impact), supported by the Romanian Executive Agency for Higher Education, Research, Development and Innovation Funding-UEFISCDI, grant number PN-III-P4-IDPCE-2016-0017.

\section{REFERENCES}

[1] Dragomir S., Dragomir G., 2014, Risk Assessment and Environmental Security, Editura Fundatiei Universitare "Danubius" Galati, ISBN978973-627-453-4.
[2] Brown J., August 05, 2015, How to Calculate Coefficient of Performance, ISSN: 1360-0648Publisher of Academic Books.

[3] Journal of heating System HYPERLINK http://en.wikipedia.org/w/index.php?title=Journal_of _Water_Supply_Research_and_Technology\&action= edit\&redlink=1" Research and Technology, ISSN: 0003-7214, 2018-IWA Publishing.

[4] Council of Europe Directive 1999/31/EC, (HG 349/2005 and Ord. Ministry 757/2004).

[5] Bendea C., Antal C., Rosca, M., 2015, Geothermal energy in Romania: country update 2010-2014. Proceedings of the World Geothermal Congress 2015, Melbourne, Australia.

[6] High Efficiency Electric Water Heater - Vaughn, August 8, 2014, http://www.vaughncorp.com/ [accessed May 2019]. 